\title{
Reciprocal associations between depression, anxiety and work-related injury
}

\author{
Vaiva Gerasimaviciute $\bullet 10,{ }^{1}$ Ute Bültmann, ${ }^{2}$ Pamela M Diamond, ${ }^{1}$ Jessica M Tullar, ${ }^{1}$ \\ George L Delclos, ${ }^{3}$ David Gimeno Ruiz de Porras, ${ }^{3}$ Benjamin C Amick III ${ }^{4,5}$
}

- Additional material is published online only. To view please visit the journal online (http://dx.doi.org/10.1136/ injuryprev-2019-043403).

${ }^{1}$ The University of Texas Health Science Center at Houston School of Public Health,

Houston, Texas, United States ${ }^{2}$ Department of Health Sciences, Community and Occupational Medicine, University of Groningen, University Medical Center Groningen, Groningen, The Netherlands

${ }^{3}$ Southwest Center for

Occupational and Environmental Health, The University of Texas Health Science Center at Houston School of Public Health, Houston, Texas, United States

${ }^{4}$ Robert Stempel College of Public Health and Social Work, Florida International University, Miami, Florida, United States ${ }^{5}$ Institute for Work and Health, Toronto, Ontario, Canada

Correspondence to Dr Benjamin C Amick III, Robert Stempel College of Public Health and Social Work, Florida International University, Miami, FL 33174, USA; bamickii@ fiu.edu

Received 22 July 2019 Revised 11 October 2019 Accepted 16 October 2019 Published Online First 4 November 2019

Check for updates

(C) Author(s) (or their employer(s)) 2020. No commercial re-use. See rights and permissions. Published by BMJ.

To cite: Gerasimaviciute $V_{\text {, }}$ Bültmann U, Diamond PM et al. Inj Prev

2020:26:529-535.

\section{ABSTRACT \\ Objective To examine the reciprocal longitudinal} associations between depression or anxiety with work-related injury (WRI) at a large employer in the southwestern United States.

Method Three administrative datasets (2011-2013) were merged: employee eligibility, medical and prescription claims, and workers' compensation claims. The sample contained 69066 active employees. Depression and anxiety were defined as episodes of medical visits care (ie, claims) with corresponding ICD9-CM codes. For an individual's consecutive claims, a new case of depression or anxiety was defined if more than 8 weeks have passed since the prior episode. The presence of a workers' compensation injury claim was used to identify WRI. Three-wave (health plan years 2011 or T1, 2012 or T2, and 2013 or T3) autoregressive cross-lagged models were used to estimate whether depression or anxiety predicted WRI, also if WRI predicted depression or anxiety in the following year(s). Results Depression predicted injury from T1 to T2 $(\beta=0.127, p<0.001)$ and from T2 to T3 $(\beta=0.092$, $p=0.001)$. Injury predicted depression from T1 to T3 $(\beta=0.418, p<0.001)$. Effects of anxiety on WRI were small and inconsistent, from T1 to T2 $(\beta=0.013$, $p=0.622)$ and from T2 to T3 $(\beta=-0.043, p=0.031)$. T1 injury had a protective effect on T3 anxiety $(\beta=-0.273$, $p<0.001$ ).

Conclusions We found evidence of reciprocal effects for depression with WRI after adjustment for prior injuries and depression. The evidence for the relationship between anxiety and WRI is less clear. WRI prevention and management programmes should incorporate depression prevention and management.

\section{INTRODUCTION}

Approximately 374 million non-fatal workrelated injuries (WRIs) occur each year across the world, each resulting in more than 4 days of nonattendance. ${ }^{1}$ This contributes to an annual loss of $4 \%$ in global gross domestic product. ${ }^{1}$ Mental illness is responsible for one-third (32.4\%) of global years lived with disability ${ }^{2}$ and a yearly loss of close to 12 billion working days. ${ }^{3}$ Depression and anxiety are among the most prevalent mental disorders and represent the greatest burden. ${ }^{2}{ }^{4}$ Despite the tremendous economic losses, few studies have considered the inter-relationship between WRI and mental health problems.

Several authors reported a significantly greater risk of WRI among employees with a history of mental disorders, ${ }^{56}$ especially among the depressed compared with those with no depression. ${ }^{7}$ Experts theorise that mental disorders increase an employee's injury risk by creating less awareness or focus, consequently leading to workers being inattentive to or missing potential work hazards, which in turn may lead to a WRI. ${ }^{5}$ One longitudinal study examined the reverse relationship and showed an increased risk of depression among workers with WRI (compared to those with non-WRI). ${ }^{8}$ The proposed mechanism was that, after the WRI, factors such as disability, protracted wage replacement, delayed return to work and/or loss of job may contribute to negative mental health outcomes. ${ }^{8}$

Plausible evidence for a reciprocal relationship of depression or anxiety with WRI is only indirect (ie, from unidirectional studies) since no studies have adequately evaluated the directionality of the association of depression and anxiety with WRI. Moreover, no longitudinal studies have controlled for the history of either of these health outcomes. Controlling for a prior history of the outcome rules out the possibility that the association is observed simply because predictor and outcome were correlated at some previous time point. ${ }^{9}$ Lastly, although depression and anxiety are the two most prevalent mental disorders in the USA ${ }^{10}$ and globally, ${ }^{2}$ there is no literature on the relationship between anxiety and WRI.

We tested whether depression or anxiety predicts WRI and, reciprocally, whether WRI predicts depression or anxiety. Further, we examined if associations differ for minor and major WRIs.

\section{METHODS}

\section{Study sample}

The study population consisted of employees from a large southwestern university system (16 institutions; hereafter referred to as the 'university system'). De-identified administrative datasets were integrated for 2011-2013, including an employee eligibility file describing who was enrolled in the health plan, a medical/prescription claims file and a workers' compensation claims file for those employees who had filed a worker's compensation claim. The annual enrolment period for the health plan was from 1 September through 31 August of each year.

A total of 202102 individuals were enrolled in the health plan for at least one full year in 20112013. Enrollee children and spouses $(n=90114)$ and employees less than 18 years old $(n=12)$ were excluded. Only enrollees with active employment status were included $(n=89367)$. All other enrollees 
(eg, retired, on sick leave) were excluded $(n=22609)$. Finally, active enrollees who were employed in only one calendar year were excluded $(n=20301)$ since the analysis focuses on crossyear associations requiring an individual to be in the analytic sample for at least 2 years. The final analytic sample consisted of 69066 active employees.

\section{Jurisdictional context}

Health insurance coverage for many workers in the USA is offered through their employers, typically as part of the employee benefits package. In our study, university employees were eligible to enrol in the health plan if they worked at least 20 hours per week for at least 135 calendar days. Although employees could opt out, and purchase a private insurance plan or get on their spouse's insurance, this is unlikely given the university's health plan provides a broad and good coverage at a competitively cheap price.

In addition, the university runs a self-insured Workers' Compensation Insurance (WCI) programme, which covers injury-related or illness-related medical costs. In some cases, it may also cover wage replacement. Unlike the health plan, the university's WCI programme is a legal obligation that operates under State's law and covers every employee. Funds for the WCI programme at each institution are allocated based on the premium allocation rate (PAR). PARs per US $\$ 100$ payroll at each institution are calculated based on the previous 3-year injury experience (number of injuries, types of injuries and cost of each incident). A higher PAR represents a greater level of injury risk, thus more compensation funds assigned to the institution.

\section{Main measures}

The presence of a workers' compensation injury claim filed within health plan years 2011, 2012 or 2013 was used to identify WRI. No injury type was excluded (note: there were no psychological injury claims filed or awarded). If no injury claim existed in a year, the employee was considered free of WRI for that year. There were 2141 employees with an injury claim. For employees with multiple WRIs $(3.5 \%$ to $4.6 \%$ of cases depending on the year), their first WRI for that year was identified.

Depression or anxiety were identified in the medical/prescription claims dataset according to ICD-9-CM $\operatorname{codes}^{11}$ (online supplementary table 1). The codes in the dataset refer to the diagnosis during the medical visit. Employees with medical visit dates which included depression or anxiety codes were coded as having depression or anxiety, and correspondingly, as not having either. Following Kessler $e t$ al, a new case of depression or anxiety was defined as an episode of care (ie, claim) preceded by at least 56 days ( 8 weeks) of no similar visits. ${ }^{12}$ This episode of psychiatric care construction was used in several other studies. ${ }^{13-15}$ The data on psychotropic drug prescriptions were not used in defining an episode to avoid misclassification bias (ie, some antidepressants might be prescribed to treat anxiety). Psychotropic drug use instead was included in the analysis as a covariate.

\section{Covariates}

Several time-fixed variables were included: age at the cohort start date (in years), gender $($ female $=1)$, institution type (academic institutions where main activities are education and research vs health science centres with additional focus on clinical services), presence of anxiety, presence of depression, psychotropic drug use and the institution's PAR (lower vs higher) for the year 2014. The PAR ranged from 0.05 to 0.19 .
Eight institutions with PAR $<0.12$ were assigned to the lower PAR category, and eight institutions with PAR $\geq 0.12$ were assigned to higher PAR category. Chronic condition count was considered in early modelling efforts. However, this variable did not show significance and was dropped to keep models more parsimonious.

\section{Data analysis}

A three-wave (T1-health plan year 2011, T2-health plan year 2012 and T3-health plan year 2013) panel was built in Mplus (V.7.4). ${ }^{16}$ This approach allows main variables to serve as predictors and outcomes simultaneously. Autoregressive coefficients were used to measure the ability of the variable to predict itself over time. ${ }^{9}$ Cross-lagged coefficients indicated the effects of one variable on another variable at later time points, after controlling for the baseline value of the outcome. ${ }^{9}$ The robust weighted least squares estimator (WLSMV) was used due to the large number of subjects, categorical outcomes and to address residual correlations. ${ }^{17}$

The baseline model (M1—autoregressive model) measured if depression predicts future depression in the first year after a diagnosis (or if anxiety predicts future anxiety) and if a WRI predicts a WRI in the first year after the injury report (figure 1). M1 did not test cross-lagged associations. All covariates were time fixed, therefore, added at T1 only as part of the baseline model.

Model fit was assessed using Comparative Fit Index (CFI), Tucker-Lewis Index (TLI) and Root Mean Square Error of Approximation (RMSEA). ${ }^{18}$ CFI and TLI values of 0.95 or greater and RMSEA less than 0.05 indicated a good fit. ${ }^{18}$ Nested models were compared using the $\chi^{2}$ difference test for the WLSMV. ${ }^{16} \mathrm{~A} p$ value greater than 0.05 implied that more restrictive models with more $\mathrm{df}$ could not to be rejected. ${ }^{19}$ The use of WLSMV estimator to model bivariate outcomes resulted in probit regression estimates. Positive estimates of the final model indicated that an increase in the predictor increased the probability of the outcome. ${ }^{20} \mathrm{~A}$ two-sided $\mathrm{p}$ value of 0.05 was used as a cut-off for the significance of the estimates.

Competing models were tested in three steps. Below, we describe the process of model testing for depression and WRI. The same modelling process was used for anxiety and WRI.

Step 1. Models for hypothesised direction of association were compared following Farrell. ${ }^{21}$ Model M1 (baseline) tested the hypothesis of no association between depression and WRI. Model M2 tested if depression predicts WRI (paths added depression $_{\mathrm{T} 1} \rightarrow \mathrm{WRI}_{\mathrm{T} 2}$ and depression $\mathrm{T}_{\mathrm{T} 2} \rightarrow \mathrm{WRI}_{\mathrm{T} 3}$ ). Model M3 (alternative to the model M2) tested if WRI predicts depression (paths added $\mathrm{WRI}_{\mathrm{T} 1} \rightarrow$ depression $\mathrm{T}_{2}$ and $\mathrm{WRI}_{\mathrm{T} 2} \rightarrow$ depression $_{\mathrm{T} 3}$ ). Model M4 (reciprocal) tested both directions of association, that is, paths in M2 and M3 (paths added depres$\operatorname{sion}_{\mathrm{T} 1} \rightarrow \mathrm{WRI}_{\mathrm{T} 2}$, depression $\mathrm{T}_{2} \rightarrow \mathrm{WRI}_{\mathrm{T} 3}, \mathrm{WRI}_{\mathrm{T} 1} \rightarrow$ depression $_{\mathrm{T} 2}$ and $\mathrm{WRI}_{\mathrm{T} 2} \rightarrow$ depression $_{\mathrm{T} 3}$ ).

After the direction of association was established, steps 2 and 3 tested if models with paths indicating longer effects over time (from T1 to T3) fit the data better.

Step 2. Two-year autoregressive lags were added and model fit was compared with the best fit model from step 1. Model M5 test if depression predicts a new case of depression in the second year after the diagnosis (path added depression ${ }_{\mathrm{T} 1} \rightarrow$ depression $_{\mathrm{T} 3}$ ). Model M6 tested if WRI predicts WRI in the second year after the injury (path added $\mathrm{WRI}_{\mathrm{T} 1} \rightarrow \mathrm{WRI}_{\mathrm{T} 3}$ ). Model M7 tested both sets of paths in M5 and M6 (paths added depression ${ }_{\mathrm{T} 1}$ to depression $_{\mathrm{T} 3}, \mathrm{WRI}_{\mathrm{T} 1} \rightarrow \mathrm{WRI}_{\mathrm{T} 3}$ ). 


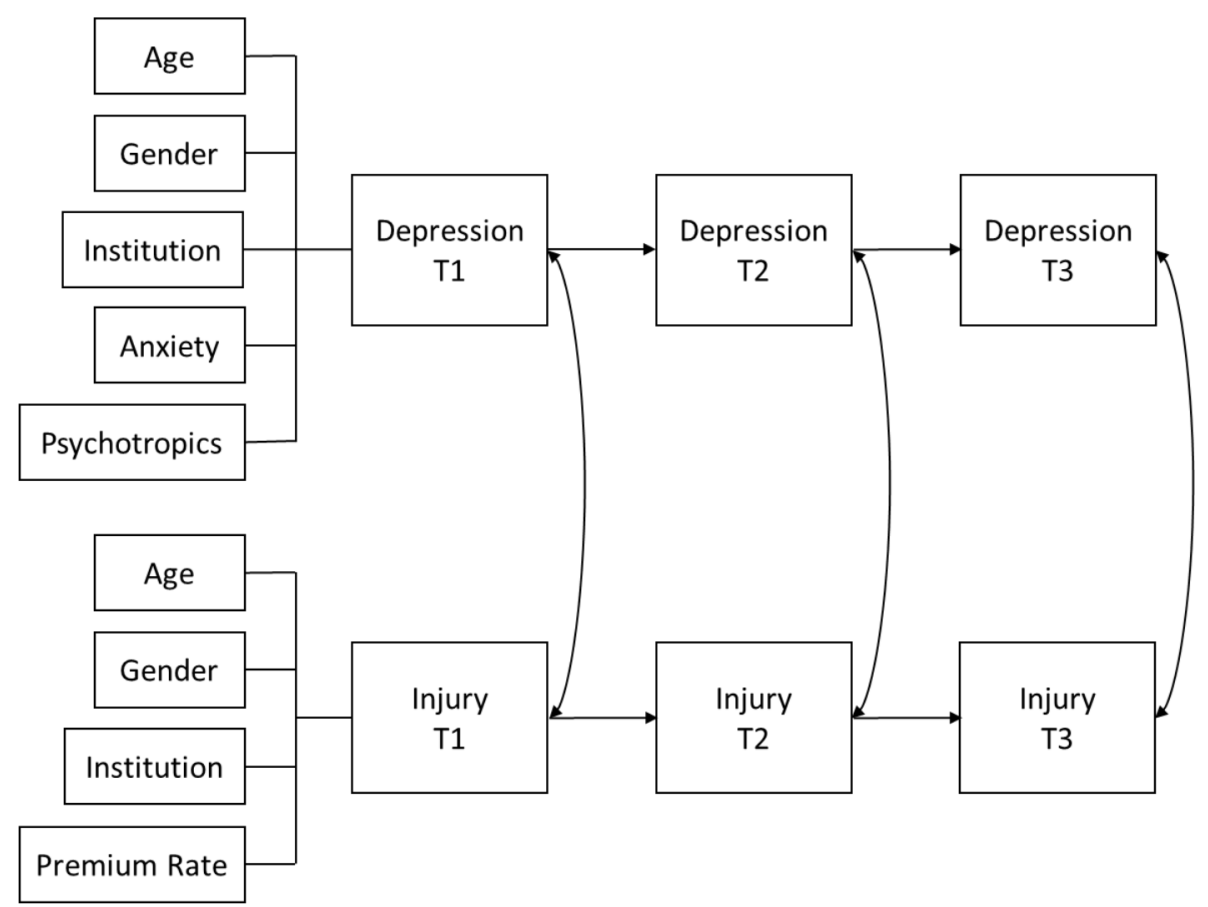

Figure 1 Baseline model for the association of depression with a work-related injury among public university employees in southwestern United States in 2011-2013.

Step 3. The best fitting model from step 2 was compared with models testing cross-lagged associations in the second year after the depression diagnosis or WRI report. Model M8 tested if depression predicts WRI in the second year after the depression diagnosis (path added depression $\mathrm{T}_{\mathrm{T}} \rightarrow \mathrm{WRI}_{\mathrm{T} 3}$ ). Model M9 tested if WRI predicts depression in the second year after the WRI (path added $\mathrm{WRI}_{\mathrm{T} 1} \rightarrow$ depression $_{\mathrm{T} 3}$ ). Model M10 tested both sets of paths in M8 and M9 (paths added depression ${ }_{\mathrm{T} 1} \rightarrow \mathrm{WRI}_{\mathrm{T} 3}$, $\mathrm{WRI}_{\mathrm{T} 1} \rightarrow$ depression $_{\mathrm{T} 3}$ ). The best fit model in step 3 was selected as the final model.

\section{Subgroup analyses}

We conducted an additional set of analyses to test the reciprocal associations between depression or anxiety with minor versus major WRIs. Initial treatment received by the employee immediately after the WRI and the time lost from work were used as a proxy for injury severity. WRIs were categorised as minor if medical treatment was not needed or if there was a minor treatment provided on site, at the clinic, at the hospital or at the emergency room. Major WRIs consisted of those where an employee was hospitalised for more than 24 hours, if there was more than 1 day lost from work (not counting the day of injury) or if employee was referred for specialised medical care.

\section{RESULTS}

\section{Study population}

Table 1 shows demographic and other baseline population characteristics $(n=69066)$. Three percent $(n=2141)$ of the population had at least one injury. Some employees had WRIs in multiple years, hence the total number of WRIs was 2296. There were 1319 minor and 977 major WRIs over the study period. Sprains or soft-tissue injuries constituted 34.6\%; haematomas, contusions and crush injuries, $24.3 \%$; lacerations or open wounds, $17.3 \%$; fractures or dislocations, 5.1\%; and burns, $2.2 \%$ of all WRIs. Six percent $(n=4114)$ of the population had

Table 1 Characteristics of the employees at a public university in southwestern United States, 2011-2013

\begin{tabular}{|c|c|c|c|c|c|c|c|}
\hline \multirow[b]{2}{*}{ Characteristic } & \multicolumn{2}{|l|}{$\begin{array}{l}\text { Work-related } \\
\text { injury, } \%\end{array}$} & \multicolumn{2}{|c|}{ Depression, \% } & \multicolumn{2}{|l|}{ Anxiety, \% } & \multirow{2}{*}{$\begin{array}{l}\text { Total } \\
\mathrm{n}=69066\end{array}$} \\
\hline & Yes $n=2141$ & No $n=66925$ & Yes $n=4165$ & No $n=64901$ & Yes $n=3686$ & No $n=65380$ & \\
\hline Mean age (SD) & $46.3(11.4)$ & $43.6(12.0)$ & 43.5 (11.2) & $43.6(12.0)$ & $41.9(11.2)$ & $43.7(12.0)$ & $43.6(12.0)$ \\
\hline Female & 61.7 & 57.8 & 71.8 & 57.0 & 68.2 & 57.3 & 57.9 \\
\hline \multicolumn{8}{|l|}{ Institution } \\
\hline Academic & 44.1 & 40.4 & 43.0 & 40.3 & 50.1 & 39.9 & 40.5 \\
\hline Health science centre & 55.9 & 59.6 & 57.0 & 59.7 & 49.9 & 60.1 & 59.5 \\
\hline \multicolumn{8}{|l|}{ Premium allocation } \\
\hline Lower $(<0.12)$ & 43.5 & 60.6 & 57.2 & 60.2 & 61.2 & 60.0 & 60.1 \\
\hline Higher ( $\geq 0.12)$ & 56.5 & 39.4 & 42.8 & 39.8 & 38.8 & 40.0 & 39.9 \\
\hline Depression & 6.5 & 5.9 & & & 26.4 & 4.8 & 6.0 \\
\hline Anxiety & 6.3 & 5.3 & 23.4 & 4.1 & & & 5.3 \\
\hline Psychotropics & 31.5 & 25.1 & 79.3 & 21.8 & 72.1 & 22.6 & 25.3 \\
\hline
\end{tabular}


Table 2 Model comparisons for the association of depression with a work-related injury among public university employees in southwestern United States, 2011-2013

\begin{tabular}{|c|c|c|c|c|c|c|c|c|}
\hline Step 1 & & & & & & vs M1 (base) & vs M2 & vs M3 \\
\hline Model & df & $\chi^{2}$ & $\mathrm{CFI}$ & TLI & RMSEA & $\Delta \chi^{2}(\mathrm{df}), \mathrm{p}$ value & $\Delta \chi^{2}(\mathrm{df}), \mathrm{p}$ value & $\Delta \chi^{2}(\mathrm{df}), \mathrm{p}$ value \\
\hline M1 (base)* & 35 & 657.13 & 0.972 & 0.960 & 0.016 & & & \\
\hline $\mathrm{M} 2 \dagger$ & 33 & 656.47 & 0.972 & 0.957 & 0.017 & $9.38(2), 0.009$ & & \\
\hline M3‡ & 33 & 585.08 & 0.976 & 0.962 & 0.016 & $77.77(2),<0.001$ & Not nested & \\
\hline M4§ & 31 & 542.48 & 0.977 & 0.963 & 0.015 & $116.51(4),<0.001$ & $118.80(2),<0.001$ & $44.34(2),<0.001$ \\
\hline Step 2 & & & & & & vs M4 & vs M5 & vs M6 \\
\hline Model & df & $\chi^{2}$ & CFI & TLI & RMSEA & $\Delta \chi^{2}(\mathrm{df}), \mathrm{p}$ value & $\Delta \chi^{2}(\mathrm{df}), \mathrm{p}$ value & $\Delta \chi^{2}(\mathrm{df}), \mathrm{p}$ value \\
\hline M5ๆ & 30 & 482.21 & 0.980 & 0.966 & 0.015 & $81.06(1),<0.001$ & & \\
\hline$M 6^{* *}$ & 30 & 478.10 & 0.980 & 0.966 & 0.015 & $65.12(1),<0.001$ & Not nested & \\
\hline M7t† & 29 & 426.39 & 0.982 & 0.969 & 0.014 & $130.73(2),<0.001$ & $56.13(1),<0.001$ & $67.45(1),<0.001$ \\
\hline Step 3 & & & & & & vs M7 & vs M8 & vs M9 \\
\hline Model & df & $\chi^{2}$ & $\mathrm{CFI}$ & TLI & RMSEA & $\Delta \chi^{2}(\mathrm{df}), \mathrm{p}$ value & $\Delta \chi^{2}(\mathrm{df}), \mathrm{p}$ value & $\Delta \chi^{2}(\mathrm{df}), \mathrm{p}$ value \\
\hline M8ł‡ & 28 & 424.81 & 0.982 & 0.968 & 0.014 & $0.96(1), 0.327$ & & \\
\hline M9§§ & 28 & 368.70 & 0.985 & 0.973 & 0.013 & $197.80(1),<0.001$ & Not nested & \\
\hline M10ๆी & 27 & 366.63 & 0.985 & 0.972 & 0.013 & $68.74(2),<0.001$ & $72.16(1),<0.001$ & $1.36(1), 0.244$ \\
\hline
\end{tabular}

${ }^{*} \mathrm{M} 1$ : first-order autoregressive associations only.

TM2: M1 plus paths from depression at T1 to injury at T2 and from depression at T2 to injury at T3.

¥M3: M1 plus paths from injury at T1 to depression at T2 and from injury at T2 to depression at T3.

§M4: M1 plus paths from depression at T1 to injury at T2, from depression at T2 to injury at T3, from injury at T1 to depression at T2 and from injury at T2 to depression at T3.

ๆM5: M4 plus path from depression at T1 to depression at T3.

** M6: M4 plus path from injury at T1 to injury at T3.

††M7: M4 plus paths from depression at T1 to depression at T3 and from injury at T1 to injury at T3.

¥¥M8: M7 plus path from depression at T1 to injury at T3.

$\S \S \mathrm{M}$ : M7 plus path from injury at T1 to depression at T3.

१ๆआ10: M7 plus paths from depression at T1 to injury at T3 and from injury at T1 to depression at T3.

$\Delta \chi^{2}$, chi-square difference test; base, baseline model; CFI, Comparative Fit Index; RMSEA, Root Mean Square Error of Approximation; TLI, Tucker-Lewis Index.

at least one new case of depression, and 5\% $(n=3646)$ had at least one new case of anxiety during the study period.

\section{Association between depression and WRI}

As table 2 shows, the baseline model including only autoregressive associations (M1) demonstrated a good fit $\left(\chi^{2}(35)=657.13\right.$, $\mathrm{CFI}=0.972, \mathrm{TLI}=0.960, \mathrm{RMSEA}=0.016)$. Comparisons of the baseline model with all other models in three steps resulted in a best fit model M9 $\left(\chi^{2}(28)=368.70, \mathrm{CFI}=0.985\right.$, TLI $=0.973$, RMSEA $=0.013)$. Adding the additional path in M10 did not improve model fit over M9 (M9 vs M10 $\Delta \chi^{2}(1)=1.36, \mathrm{p}=0.24$ ). All steps in the process are shown in table 2.

The final model 9 is shown in figure 2. Depression predicted future WRI $\left(\beta_{\mathrm{T} 1 \rightarrow \mathrm{T} 2}=0.127, \mathrm{p}<0.001, \beta_{\mathrm{T} 2 \rightarrow \mathrm{T} 3}=0.092, \mathrm{p}=0.001\right)$. The path coefficients from injury to depression were significant but inconsistent. T1 WRI increased the likelihood of depression at $\mathrm{T} 2\left(\beta_{\mathrm{T} 1 \rightarrow \mathrm{T} 2}=0.310, \mathrm{p}<0.001\right)$ and $\mathrm{T} 3 \quad\left(\beta_{\mathrm{T} 1 \rightarrow \mathrm{T} 3}=0.418\right.$, $\mathrm{p}<0.001)$ while WRI at T2 was protective against depression at $\mathrm{T} 3\left(\beta_{\mathrm{T} 2 \rightarrow \mathrm{T} 3}=-0.147, \mathrm{p}=0.001\right)$. Depression predicted future depression $\left(\beta_{\mathrm{T} 1 \rightarrow \mathrm{T} 2}=0.929, \mathrm{p}<0.001, \quad \beta_{\mathrm{T} 1 \rightarrow \mathrm{T} 2}=0.261\right.$, $\left.\mathrm{p}<0.001, \beta_{\mathrm{T} 1 \rightarrow \mathrm{T3}}=0.684, \mathrm{p}<0.001\right)$. WRI predicted future WRI $\quad\left(\beta_{\mathrm{T} 1 \rightarrow \mathrm{T} 2}=0.477, \quad \mathrm{p}<0.001, \quad \beta_{\mathrm{T} 2 \rightarrow \mathrm{T} 3}=0.214, \quad \mathrm{p}<0.001\right.$, $\left.\beta_{\mathrm{T} 1 \rightarrow \mathrm{T} 3}=0.296, \mathrm{p}<0.001\right)$. For all final models, regression coefficients, SEs and $\mathrm{p}$ values can be found in online supplementary table 2 .

\section{Association between anxiety and WRI}

As table 3 shows, the baseline model M1 (base) indicated a good fit $\left(\chi^{2}(35)=724.42, \mathrm{CFI}=0.944, \mathrm{TLI}=0.919\right.$, $\left.\mathrm{RMSEA}=0.017\right)$. Comparisons of the baseline model with all other models resulted in a best fit model M9 $\left(\chi^{2}(28)=467.18\right.$, CFI $=0.964$, $\mathrm{TLI}=0.935, \mathrm{RMSEA}=0.015)$. Adding the additional path in M10 did not improve model fit over M9 (M9 vs M10 $\Delta \chi^{2}(1)=1.35$, $\mathrm{p}=0.245)$. All steps in the process are shown in table 3 .

Model M9 for anxiety is shown in figure 3. Anxiety did not predict WRI $\left(\beta_{\mathrm{T} 1 \rightarrow \mathrm{T} 2}=0.013, \mathrm{p}=0.622, \beta_{\mathrm{T} 2 \rightarrow \mathrm{T} 3}=-0.043\right.$,

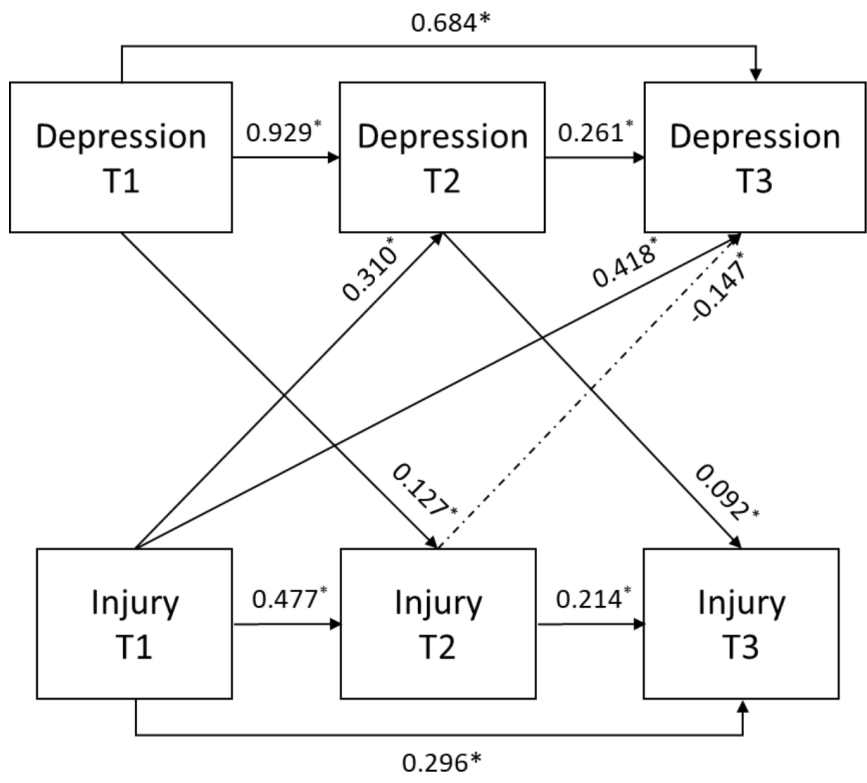

Figure 2 Standardised estimates for the association of depression with a work-related injury among public university employees in southwestern United States in 2011-2013. Adjusted for age, gender, psychotropic drug use, presence of anxiety, type of institution and premium allocation rate. *Significant at $p<0.05$. Dotted line identifies negative coefficient. 
Table 3 Model comparisons for the association of anxiety with a work-related injury among public university employees in southwestern United States, 2011-2013

\begin{tabular}{|c|c|c|c|c|c|c|c|c|}
\hline Step 1 & & & & & & vs M1 (base) & vs M2 & vs M3 \\
\hline Model & $d f$ & $\chi^{2}$ & CFI & TLI & RMSEA & $\Delta \chi^{2}(\mathrm{df}), \mathrm{p}$ value & $\Delta \chi^{2}(\mathrm{df}), \mathrm{p}$ value & $\Delta \chi^{2}(\mathrm{df}), \mathrm{p}$ value \\
\hline M1 (base)* & 35 & 724.42 & 0.944 & 0.919 & 0.017 & & & \\
\hline $\mathrm{M} 2 \dagger$ & 33 & 725.75 & 0.944 & 0.913 & 0.017 & $6.90(2), 0.032$ & & \\
\hline M3‡ & 33 & 666.87 & 0.949 & 0.921 & 0.017 & $60.29(2),<0.001$ & Not nested & \\
\hline M4§ & 31 & 667.92 & 0.949 & 0.915 & 0.017 & $61.60(4),<0.001$ & $59.73(2),<0.001$ & $5.50(2), 0.064$ \\
\hline Step 2 & & & & & & vs M3 & vs M5 & vs M6 \\
\hline Model & df & $\chi^{2}$ & $\mathrm{CFI}$ & TLI & RMSEA & $\Delta \chi^{2}(\mathrm{df}), \mathrm{p}$ value & $\Delta \chi^{2}(\mathrm{df}), \mathrm{p}$ value & $\Delta \chi^{2}(\mathrm{df}), \mathrm{p}$ value \\
\hline M5ף & 30 & 553.71 & 0.958 & 0.928 & 0.016 & $118.06(3),<0.001$ & & \\
\hline$M 6^{* *}$ & 30 & 603.62 & 0.954 & 0.921 & 0.017 & $67.11(3),<0.001$ & Not nested & \\
\hline M7t† & 29 & 490.10 & 0.963 & 0.934 & 0.015 & $182.33(4),<0.001$ & $64.44(1),<0.001$ & $147.71(1),<0.001$ \\
\hline Step 3 & & & & & & vs M7 & vs M8 & vs M9 \\
\hline Model & df & $\chi^{2}$ & $\mathrm{CFI}$ & TLI & RMSEA & $\Delta \chi^{2}(\mathrm{df}), \mathrm{p}$ value & $\Delta \chi^{2}(\mathrm{df}), \mathrm{p}$ value & $\Delta \chi^{2}(\mathrm{df}), \mathrm{p}$ value \\
\hline M8キ‡ & 28 & 488.25 & 0.963 & 0.932 & 0.015 & $1.42(1), 0.233$ & & \\
\hline M9§§ & 28 & 467.18 & 0.964 & 0.935 & 0.015 & $23.07(1),<0.001$ & Not nested & \\
\hline M10ๆף & 27 & 465.36 & 0.965 & 0.933 & 0.015 & $24.41(2),<0.001$ & $23.03(1),<0.001$ & 1.35 (1), 0.245 \\
\hline
\end{tabular}

${ }^{*} \mathrm{M} 1$ (base): first-order autoregressive associations only.

TM2: M1 plus paths from anxiety at T1 to injury at T2 and from anxiety at T2 to injury at T3.

¥M3: M1 plus paths from injury at T1 to anxiety at T2 and from injury at T2 to anxiety at T3.

§M4: M1 plus paths from anxiety at T1 to injury at T2, from anxiety at T2 to injury at T3, from injury at T1 to anxiety at T2 and from injury at T2 to anxiety at T3.

ๆM5: M4 plus path from anxiety at T1 to anxiety at T3.

** M6: M4 plus path from injury at T1 to injury at T3.

††M7: M4 plus paths from anxiety at T1 to anxiety at T3 and from injury at T1 to injury at T3.

¥¥M8: M7 plus path from anxiety at T1 to injury at T3.

$\S \S \mathrm{M9:}$ M7 plus path from injury at T1 to anxiety at T3.

ๆๆM10: M7 plus paths from anxiety at $\mathrm{T} 1$ to injury at $\mathrm{T} 3$ and from injury at $\mathrm{T} 1$ to anxiety at $\mathrm{T} 3$.

$\Delta \chi^{2}$, chi-square difference test; base, baseline model; CFI, Comparative Fit Index; RMSEA, Root Mean Square Error of Approximation; TLI, Tucker-Lewis Index.

$\mathrm{p}=0.175)$. WRI at T1 was protective against anxiety at T3 $\left(\beta_{\mathrm{T} 1 \rightarrow \mathrm{T} 3}=-0.273, \mathrm{p}<0.001\right)$, but 1-year associations were inconsistent $\left(\beta_{\mathrm{T} 1 \rightarrow \mathrm{T} 2}=-0.291, \mathrm{p}<0.001, \beta_{\mathrm{T} 2 \rightarrow \mathrm{T} 3}=0.047, \mathrm{p}=0.276\right)$. Autoregressive coefficients indicated that anxiety predicted future anxiety $\left(\beta_{\mathrm{T} 1 \rightarrow \mathrm{T} 2}=0.838, \quad \mathrm{p}<0.001, \quad \beta_{\mathrm{T} 2 \rightarrow \mathrm{T} 3}=0.269\right.$, $\left.\mathrm{p}<0.001, \beta_{\mathrm{T} 1 \rightarrow \mathrm{T} 3}=0.567, \mathrm{p}<0.001\right)$ and WRI predicted future

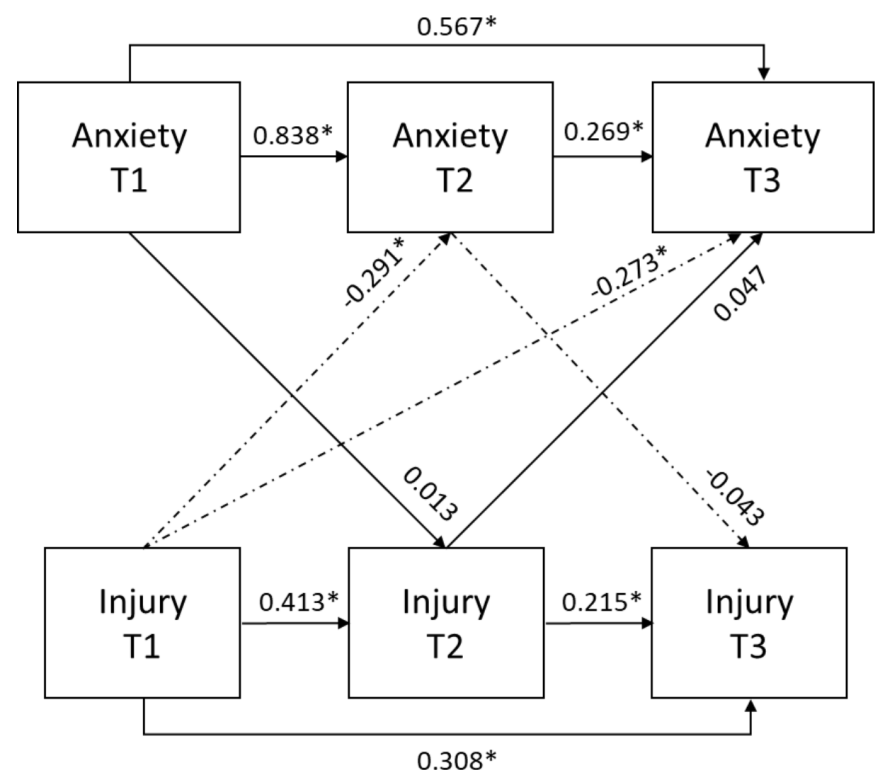

Figure 3 Standardised estimates for the association of anxiety with a work-related injury among public university employees in southwestern United States in 2011-2013. Adjusted for age, gender, psychotropic drug use, presence of depression, type of institution and premium allocation rate. *Significant at $p<0.05$. Dotted line identifies negative coefficient.
WRI $\quad\left(\beta_{\mathrm{T} 1 \rightarrow \mathrm{T} 2}=0.413, \quad \mathrm{p}<0.001, \quad \beta_{\mathrm{T} 2 \rightarrow \mathrm{T} 3}=0.215, \quad \mathrm{p}<0.001\right.$, $\left.\beta_{\mathrm{T} 1 \rightarrow \mathrm{T} 3}=0.308, \mathrm{p}<0.001\right)$. The complete list of regression coefficients, SEs and $p$ values of the final model can be found in online supplementary table 3 .

\section{Minor and major WRIs}

Model comparisons for the association between depression and major WRI can be found in online supplementary table 4 . Depression consistently predicted major WRI in the next year after the diagnosis $\left(\beta_{\mathrm{T} 1 \rightarrow \mathrm{T} 2}=0.136, \mathrm{p}<0.001, \beta_{\mathrm{T} 2 \rightarrow \mathrm{T} 3}=0.114\right.$, $\mathrm{p}=0.002$ ) (online supplementary figure 1 ). T1 major WRI increased the risk of depression at T2 $\left(\beta_{\mathrm{T} 1 \rightarrow \mathrm{T} 2}=0.410, \mathrm{p}<0.001\right)$ and T3 $\left(\beta_{\mathrm{T} 1 \rightarrow \mathrm{T} 3}=0.553, \mathrm{p}<0.001\right)$, but the path from T2 to T3 was not significant $\left(\beta_{\mathrm{T} 2 \rightarrow \mathrm{T} 3}=-0.088, \mathrm{p}=0.125\right)$.

Model comparisons for the association between depression and minor WRI are shown in online supplementary table 5 . Depression predicted minor WRI from T1 to T2 $\left(\beta_{\mathrm{T} 1 \rightarrow \mathrm{T} 2}=0.129\right.$, $\mathrm{p}<0.001$ ), while paths from T2 to T3, and T1 to T3 were insignificant $\left(\beta_{\mathrm{T} 2 \rightarrow \mathrm{T} 3}=-0.006, \mathrm{p}=0.979, \beta_{\mathrm{T} 1 \rightarrow \mathrm{T} 3}=0.081, \mathrm{p}=0.721\right)$ (online supplementary figure 2 ). T1 minor WRI increased the risk of depression at T2 $\left(\beta_{\mathrm{T} 1 \rightarrow \mathrm{T} 2}=0.375, \mathrm{p}<0.001\right)$ and T3 $\left(\beta_{\mathrm{T} 1 \rightarrow \mathrm{T} 3}=0.663, \mathrm{p}<0.001\right)$. T2 minor $\mathrm{WRI}$ showed a protective effect against T3 depression $\left(\beta_{\mathrm{T} 2 \rightarrow \mathrm{T} 3}=-0.259, \mathrm{p}<0.001\right)$.

Model comparisons for anxiety and major WRI association can be found in online supplementary table 6 . Anxiety did not predict major WRI $\left(\beta_{\mathrm{T} 1 \rightarrow \mathrm{T} 2}=-0.016, \mathrm{p}=0.671, \beta_{\mathrm{T} 2 \rightarrow \mathrm{T} 3}=0.017\right.$, $\mathrm{p}=0.693$ ) (online supplementary figure 3 ). T1 major WRI was protective against anxiety at $\mathrm{T} 2 \quad\left(\beta_{\mathrm{T} 1 \rightarrow \mathrm{T} 2}=-0.420, \mathrm{p}<0.001\right)$ and at T3 $\left(\beta_{\mathrm{T} 1 \rightarrow \mathrm{T} 3}=-0.534, \mathrm{p}<0.001\right)$. T2 major WRI did not predict T3 anxiety $\left(\beta_{\mathrm{T} 2 \rightarrow \mathrm{T} 3}=0.089, \mathrm{p}=0.134\right)$.

Model comparisons for anxiety and minor WRI association can be found in online supplementary table 7 . T1 anxiety did not 
predict T2 minor WRI $\left(\beta_{\mathrm{T} 1 \rightarrow \mathrm{T} 2}=0.015, \mathrm{p}=0.674\right)$ (online supplementary figure 4$)$, but T2 anxiety acted protectively against T3 minor WRI $\left(\beta_{\mathrm{T} 2 \rightarrow \mathrm{T} 3}=-0.092, \mathrm{p}=0.016\right)$. T1 minor WRI was protective against anxiety at T2 $\left(\beta_{\mathrm{T} 1 \rightarrow \mathrm{T} 2}=-0.474, \mathrm{p}<0.001\right)$ and at T3 $\left(\beta_{\mathrm{T} 1 \rightarrow \mathrm{T} 3}=-0.590, \mathrm{p}<0.001\right)$. T2 major WRI did not predict $\mathrm{T} 3$ anxiety $\left(\beta_{\mathrm{T} 2 \rightarrow \mathrm{T} 3}=0.064, \mathrm{p}=0.237\right)$.

\section{DISCUSSION}

To the best of our knowledge, this is the first study to examine the reciprocal associations between depression or anxiety and WRI. Our findings suggest that there is a reciprocal association between depression and WRI such as depression predicts WRI in the first year after diagnosis, while WRI predicts depression in the second year after the WRI. One-year effects of WRI on depression showed conflicting results-one parallel path indicated that WRI increases the risk of depression, but next parallel path showed a protective effect of WRI against depression. Additional analyses by WRI severity showed that in the first year after the diagnosis, depression predicts major but not minor WRI. However, both minor and major types of WRIs predicted depression in the second year after the WRI. The protective effect of WRI on depression was driven by minor WRIs. WRI was protective against anxiety in the second year after the WRI. The associations between anxiety and minor versus major WRIs remained the same as of the main analysis.

Our findings support one previous study, ${ }^{7}$ where depression increased the risk of WRI. The effects of depression on WRI can be explained through impaired cognitive (processing speed, attention) ${ }^{22}$ and psychomotor (balance, reduced muscle strength) ${ }^{23}$ functions. The findings are also consistent with another study, where an increased risk of depression followed a WRI. ${ }^{8}$ Literature suggests three plausible mechanisms for developing depression after a WRI: (1) through impaired health, functionality and quality of life; (2) through reduced productivity at work and lower wages; (3) through mental distress of dealing with workers' compensation insurance. ${ }^{824} 25$ Aforementioned mechanisms evolve over time, which is compatible with our finding that the increased risk of depression was observed not in the first but in the second year after the injury. Unfortunately, we did not have any data to examine these mechanisms. We find it challenging to explain the conflicting effects of WRI on depression in the first year after the WRI. An increasing amount of research, exploring postinjury effects, have found a negative correlation between the resilience (ability to maintain stable psychological functioning) and depression or anxiety, that is, injured individuals with a higher levels of resilience are less likely to experience depression or anxiety. ${ }^{26} 27$ Since the population of our study was dynamic, employees at T2 might have had higher level of resilience (as compared with those at T1) resulting in better mental health outcomes. There are no longitudinal studies for us to compare our findings regarding the lower risk of anxiety after the WRI.

The findings of our study should be interpreted in the context of the following methodological considerations. First, the binary nature of the outcomes paired with the WLSMV estimator resulted in probit regression coefficients, which do not directly translate into effect size estimators. While having effect sizes would add value, the sign and statistical significance of probit estimates fully serve the study purpose. Second, defining depression or anxiety as an episode of care does not ensure the identification of new episodes of disease. Despite this being a limitation, we used a definition that has been used previously, and at the very minimum, it implies initiation of a new treatment. Third,

\section{What is already known on the subject}

- Previous studies have examined associations of depression with work-related injury, but there have been no formal evaluations of a potential reciprocal association and no studies have controlled for previous history of injuries.

ascertaining depression and anxiety through administrative data identifies only those filing a medical claim and therefore might underestimate cases where there was no medical visit. Several studies comparing depression prevalence using diagnostic scales versus administrative data found lower rates using the latter. ${ }^{28} 29$ Fourth, we might not have captured all WRIs as institutions may under-report to keep lower premium rates. ${ }^{30}$ However, the $3 \%$ injury rate in our population was similar to the occupational injury rate in the US colleges, universities and professional schools. ${ }^{31}$ Fifth, we were not able to control for the types of jobs or job hazards, as these data were not available. The different risks related to different jobs were only minimally captured by controlling for PAR and type of institution. Sixth, we were not able to examine associations by type of WRIs because some of the categories were too small. Seventh, while the latest research demonstrates the interdependence between work limitations and depression, ${ }^{32}$ we did not have return-to-work-data to account for the duration of injury. Eighth, we were not able to adjust for the non-WRI, as these data were not captured by the WCI. Lastly, we did not have data to determine plausible mechanisms of the associations.

Despite the above potential limitations, our study has many strengths such as the use of very large datasets, where depression or anxiety diagnoses were recorded independently from WRIs in a longitudinal study design; the examination, for the first time, of the reciprocal relationship between depression or anxiety and WRI using a robust method, which allows making causal inferences; controlling the associations between mental disorders and WRI for comorbid depression or anxiety, psychotropic drug use and prior WRI; capturing severe depression and anxiety, requiring treatment; testing the associations for minor and major injuries separately; and, lastly, the contribution of our study to the sparse literature investigating health risk factors among university system employees.

\section{CONCLUSION}

The relationship between common mental disorders and injury is complex. Depression predicted WRI, and reciprocally, WRI predicted depression in an employee population at a large southwestern university. We did not observe this reciprocal relationship for anxiety. While depression and anxiety are frequently studied

\section{What this study adds}

- This is the first longitudinal study to examine the reciprocal associations of depression or anxiety with work-related injury, controlling for history of prior injuries and prior depression or anxiety.

- Causal reciprocal effects between depression and workrelated injury were found so that depression can lead to injury and injury can lead to depression.

- Evidence for a reciprocal relationship between anxiety and work-related injury is mixed. 
together, our research suggests that it is critical to examine the effects of depression and anxiety on another health outcome (eg, injury) separately. Further, other studies are needed to provide insights about the mechanisms of the association between depression and WRI, for which our study was not designed. The inconsistent effects for depression on injury we observed in the first year after the injury suggest future studies may need to consider that there may be employees with different levels of resilience to mental health problems. In addition, the potential role of postinjury pain in depression development should be elucidated since it may be helpful from a disease management perspective. Workplace injury prevention programmes should consider implementing evidence-based best practices that help employees manage depression such as coping skills training, mindfulness, encouragement of seeking professional help and programmes improving mental health literacy.

Acknowledgements This work was supported by The University of Texas System Office of Employee Benefits.

Contributors VG designed the study, analysed the data and wrote the manuscript with the help of other authors. UB helped in study design, paper writing and interpreting results. PMD consulted on autoregressive cross-lagged modelling. JMT provided access to the data, software and consulted in interpreting results and drafting the manuscript. GLD consulted throughout the paper with the heaviest input on measuring WRIs and interpreting results. DGRdP consulted throughout the paper with the heaviest input on methods. BCA proposed the study design and advised drafting all sections of the paper. All authors discussed the results, reviewed the draft of the article and approved to be published.

Funding GLD and DGRP were partially funded by the Centers for Disease Control and Prevention, National Institute for Occupational Safety and Health Education and Research Center Grant [5T420H008421] to the Southwest Center for Occupational and Environmental Health at the University of Texas Health Science Center at Houston School of Public Health.

Disclaimer The content is solely responsibility of the authors and does not necessarily represent the views of the University of Texas Office of Employee Benefits.

Competing interests None declared.

Patient consent for publication Not required.

Provenance and peer review Not commissioned; externally peer reviewed.

Data availability statement All data relevant to the study are included in the article or uploaded as supplementary information.

ORCID iD

Vaiva Gerasimaviciute http://orcid.org/0000-0001-8569-5849

\section{REFERENCES}

1 International Labour Organization. Safety and health at work. Available: https://www. ilo.org/global/topics/safety-and-health-at-work/lang-en/index.htm [Accessed Jul 2019].

2 Vigo D, Thornicroft G, Atun R. Estimating the true global burden of mental illness. Lancet Psychiatry 2016;3:171-8.

3 The Lancet Commission on global mental health and sustainable development. Evidence for action on mental health and global development. Available: https://glob almentalhealthcommission.org/wp-content/uploads/2018/10/Lancet-Commission_ policy-brief_MHIN2.pdf.pdf [Accessed Jul 2019].

4 World Health Organization. Mental health at work. Available: https://www.who.int/ mental_health/in_the_workplace/en/ [Accessed Jul 2019].

5 Cherry N, Burstyn I, Beach J. Mental ill-health and second claims for work-related injury. Occup Med 2012;62:462-5.
6 Palmer KT, D'Angelo S, Harris EC, et al. The role of mental health problems and common psychotropic drug treatments in accidental injury at work: a case-control study. Occup Environ Med 2014;71:308-12.

7 Kubo J, Goldstein BA, Cantley LF, et al. Contribution of health status and prevalent chronic disease to individual risk for workplace injury in the manufacturing environment. Occup Environ Med 2014;71:159-66.

8 Kim J. Depression as a psychosocial consequence of occupational injury in the US working population: findings from the medical expenditure panel survey. BMC Public Health 2013;13:E303.

9 Laursen B, Little TD. Autoregressive and cross-lagged panel analysis for longitudinal data. In: Laursen B, Little TD, Card NA, eds. Handbook of developmental research methods. New York, NY: The Guilford Press, 2012: 265-78.

10 National Institute of Mental Health. Mental health information. Available: https:// www.nimh.nih.gov/health/statistics/index.shtml [Accessed Jun 2019].

11 Centers for Disease Control and Prevention. Centers for Disease Control and Prevention. International Classification of Diseases, Ninth Revision, Clinical Modification (ICD-9-CM). Available: https://www.cdc.gov/nchs/icd/icd9cm.htm [Accessed Jun 2019].

12 Kessler LG, Steinwachs DM, Hankin JR. Episodes of psychiatric utilization. Med Care 1980;18:1219-27.

13 Lindrooth RC, Lo Sasso AT, Lurie IZ. The effect of distance to provider on employee response to changes in mental health benefits. Health Econ 2006;15:1133-41.

14 Huskamp HA. Episodes of mental health and substance abuse treatment under a managed behavioral health care carve-out. Inquiry 1999;36:147-61.

15 McConnell KJ, Gast SHN, McFarland BH. The effect of comprehensive behavioral health parity on choice of provider. Med Care 2012;50:527-33.

16 Muthén LK, Muthén BO. Mplus user's guide. 8th edition. Los Angeles, CA: Muthén \& Muthén, 2017.

17 Muthén B, Muthén L, Asparouhov T. Estimator choices with categorical outcomes. Available: http://www.statmodel.com/download/EstimatorChoices.pdf [Accessed Jun 2019].

18 Geiser C, ed. Data analysis with Mplus. New York, NY: The Guilford Press, 2013.

19 Muthén LK, Muthén BO. Mplus discussion confirmatory factor analysis.

20 Institute for Digital Research and Education. Probit regression. Available: https://stats. idre.ucla.edu/stata/output/probit-regression [Accessed Jun 2019].

21 Farrell AD. Structural equation modeling with longitudinal data: strategies for examining group differences and reciprocal relationships. J Consult Clin Psychol 1994;62:477-87

22 Elderkin-Thompson V, Kumar A, Bilker WB, et al. Neuropsychological deficits among patients with late-onset minor and major depression. Arch Clin Neuropsychol 2003;18:529-49.

23 Hausdorff JM, Nelson ME, Kaliton D, et al. Etiology and modification of gait instability in older adults: a randomized controlled trial of exercise. J Appl Physiol 2001:90:2117-29.

24 Keogh JP, Nuwayhid I, Gordon JL, et al. The impact of occupational injury on injured worker and family: outcomes of upper extremity cumulative trauma disorders in Maryland workers. Am J Ind Med 2000;38:498-506.

25 Dembe AE. The social consequences of occupational injuries and illnesses. Am J Ind Med 2001;40:403-17.

26 Rainey EE, Petrey LB, Reynolds $\mathrm{M}$, et al. Psychological factors predicting outcome after traumatic injury: the role of resilience. The American Journal of Surgery 2014:208:517-23.

27 Bonanno GA, Kennedy P, Galatzer-Levy IR, et al. Trajectories of resilience, depression, and anxiety following spinal cord injury. Rehabil Psychol 2012;57:236-47.

28 Noyes $\mathrm{K}$, Liu H, Lyness JM, et al. Medicare beneficiaries with depression: comparing diagnoses in claims data with the results of screening. Psychiatr Serv 2011;62:1159-66.

29 Thielen $\mathrm{K}$, Nygaard E, Andersen I, et al. Misclassification and the use of register-based indicators for depression. Acta Psychiatr Scand 2009;119:312-9.

30 The Committee on Education and Labor. U.S. House of Representatives. Hidden tragedy: underreporting of workplace injuries and illnesses. Available: https://www. bls.gov/iif/laborcommreport061908.pdf [Accessed Jun 2019].

31 Bureau of Labor Statistics. Industry injury and illness data, 2017. Available: https:// www.bls.gov/iif/oshsum.htm [Accessed Sep 2019].

32 Bultmann U, Ibrahim S, Hogg-Johnson S, et al. 021-4 Trajectories of depression and work limitations in injured workers with musculoskeletal disorders: 2-year follow-up study. Occup Environ Med 2016;73:A40. 